\title{
ELECTRONIC COMPUTERS IN THE SERVICE OF BUSINESS
}

\begin{abstract}
$T$ a distance of some days, it is possible to A unscramble the many and varied impressions created at the Electronic Computer Exhibition and Business Computer Symposium (Olympia, London, November 28-December 4), and to consider what one feels are the more important implications. One may put aside such technical developments as the increas. ing use of printed cirevits in place of wiring and of transistors in place of thermionic valves: such matters are applicable to the electronics industry as a whole. One may also disregard a number of technically interesting but somewhat irrelevant demonstrations, and the bread-and-butter exhibits of stationery, fumiture and office equipment. It then becomes apparent that the most prominent feature of the Exhibition and Symposium was the emergence, in parallel, of a classic approach to the introduction of integrated electronic data-processing for business purposes, and of a fashion in the design of computer systems directed to cater for this approach.
\end{abstract}

That business has now taken over from scientific research the role of principal instigator of the development of computers can be clearly inferred not only from the types of computer system on show, but also and more directly from the fact that the majority of displays were of computer systems rather than of simple computers. The predominant trend in design is towards what Lord Halsbury in his opening address to the Symposium described as the "fully literate computer" : one which is designed to read information from the widest possible range of input media (manual keyboard, punched paper tape, punched cards and magnetic tape), and can write information on an equivalent range of output equipment; one which, moreover, can grant a considerable measure of autonomous control to its input and output facilitios so that these may proceed independently, transferring information to or from buffer storage in readiness for the central computer's demands. Such a trend must be to the gratification of one manufacturing organization, at least, which was operating electronic dataprocessing equipment on something approaching this basis at a time, four years ago, when no other general business electronic data-processing installation existed.

In an attempt tp keep up with this trend, some small and medium-sized computers have followed the tactics of the puffer fish. Though thoroughly competent in the role for which they were originally designed, these machines are being required to support a burden of peripheral equipment out of all proportion to their normal capacity. Prospective purchasers may well consider whether there can be any justification for tying upwards of $£ 100,000$ worth of input, output and ancillary storage equipmont to the apron strings of a computer which is incapable of utilizing effectively more than a small proportion of its potential activity. It was equally regrettable to note the manner in which one or two exhibitors sought to attract attention by stunts which had little or no connexion with the intended application of their equipment. "Good wine needs no bush", and an effective computer does not require a 'gimmick'.

In respect of ancillary equipment, one could discern another important trend. While mechanical equip- ment is being pushed to the utmost to achieve greater speeds of printing, punching and hole sensing, in one corner of the exhibition could be seen the allelectronic writing on the wall. A prototype printing device was on show in which the characters, delineated by deflexions of the beam of a cathode-ray tube in response to signals decoded from a magnetic tape, are used, by means of a system of optical projection and static charges, to deposit powder in appropriate shapes upon a continuously moving roll of paper. The powder is then bonded to the paper by heat treatment, emerging as a succession of lines of print to be taken upon an output roller. The speed of output by this equipment is of the order of ten times that of the most rapid mechanical line printer on show, yet the only moving parts are the slowly revolving rollers. Elsewhere could be seen prototype equipment which, by use of cathode-ray tube scanning and photo-multipliers, could, in a continuous process, read typescript characters from a document and code these in computer language on to magnetic tape. Such equipment, when perfected, will have two great advantages. High-speed mechanical equipment, particularly when reciprocating motion is involved, is not infrequently subject to mechanical breakdown. In order to avoid interrupting the flow of work while spare parts are obtained and repairs are made, it has become common practice to install an expensive spare machine which will be idle for a considerable part of the time. Moreover, the direct automatic conversion from original document to computer language and from the latter to printed output will eliminate the intermediate steps in which human errors are likely to be introduced.

The classic approach to an integrated electronic data-processing system was apparent in a welldeveloped form in three of the papers presented at the Symposium, and in an embryonic state in at least three more. It reflects the growing confidence of business management in the feasibility of such a system, as exemplified by the comment of one speaker that if his system of completely integrated data-processing did not prove satisfactory he would be obliged to seek a new occupation. This attitude is a far cry from the somewhat timid and tentative approaches to electronic data processing of some applications represented at the Symposium but not representative of it. The classic approach involves a penetrating research into the very fundamentals of the existing business system, questioning why the various functions are performed, rather than investigating the exact manner of their performance. It is essential, of course, that such an investigation should be carried out under the close direction of persons of managerial or senior supervisory calibre. Many speakers at the Symposium were agreed that it was equally necessary that the 'organization and methods' personnel concerned in investigations for an electronic data. processing system should have a sound general knowledge of programming techniques and that programmers should be acquainted with 'organization and methods' procedure. The two can then work in close collaboration to determine the nature of the 
original information available for input and that of the various types of output information which should be proved necessary or desirable. From this they would devise an efficient system for achieving the requirements, using the full range of equipment available. Carried to its logical conclusion, such an investigation should not consider the somewhat arbitrary divisions into which a business may be divided at present (for example, wages and salaries, cost accountancy, production and stock control, sales invoicing), but should include the whole scope of the business. This may sound a Utopian concept, but it is already being attempted by some, and is considered the essential goal by many others.

The essential element of such an approach is the open mind, uninhibited by existing manual or punched-card clerical systems. Some business organizations which have not yet installed mechanized systems of any kind have considered adopting a little-by-little approach; a gradual transition by introducing first a punched-card system, then a small-scale computer, and finally a fully developed large-scale computer system. To these the experience of one business organization may be of interest and provide some guidance. The spokesman of this concern explained that the computer system now being installed bears very little resemblance to the punched-card system which preceded it, although he acknowledged that the latter had provided some useful experience in planning.

It is true that the applications of a limited scope may sometimes be of outstanding importance. A saving of the order of $£ 50,000$ per annum for the expenditure of three or four hundred pounds was reported at the Symposium from the application of linear programming techniques to a problem of bulk transportation, and an account was given of how an hour or so a week on a small computer had made possible the introduction of a greatly improved method of production control. But in general, the most substantial benefits will come from a comprehensive system. This does not imply that an integrated system can be installed in one operation. The system must be planned with the view of dividing it into phases which are of such a size and nature that they may be introduced in sequence over a period of many months. The transition, indeed, requires some of the most careful and detailed planning, for each phase must be introduced with the least possible disturbance both to work already on the computer and to procedures which are still carried out manually. It is normally advisable to run each new phase on the computer in parallel with the previous system until it is reasonably certain that all eventualities have been covered. Furthermore, it is prudent to prepare in advance an emergency procedure for adoption in the event of a serious breakdown of the equipment, however unlikely this may be.

Compared with strategical planning of such complexity, the tactical programming may well prove relatively simple. However, just as interpretive routines and automatic coding techniques permit the computer to assist the programmer, so may some of the computer techniques which are being developed in the field of operational research be of assistance to the planner. A paper on developments in this field was presented at the Symposium, and the speaker agreed with a suggestion that the simulation techniques which he had described could be used to study the feasibility of systems designed for a business electronic data-processing installation. A large organization might find it worth while to acquire a small computer initially for this purpose. If this machine were compatible with the peripheral equipment of the proposed large installation, it could later be used in conjunction with it, and would prove invaluable for carrying out those housekeeping activities such as sorting and merging which occupy so much of the time of a large computer while exploiting so little of its capabilities. This, then, may represent the pattern for the future use of electronic computers in business.

In conclusion, I wish to make it plain that the opinions expressed above are of a purely personal nature, and should not be construed as representing the policy of the organization with which I am associated.
W. L. C. Garrett

\section{SCIENTIFIC CENTENARIES OF 1959}

\section{BY JOAN M. EYLES}

$\mathrm{O}^{\mathrm{N}}$ $\mathrm{NE}$ of the first requisites for the traveller is a good map of the country in which he proposes to travel. If none exists, then his travels will help to provide one. The launching of the First Crusade in 1095 by Pope Urban II marked the beginning of a series of mass pilgrimages across Europe which continued for nearly two centuries and must have given rise to a demand for maps, guides and charts to help the traveller on his way. The earliest medieval maps of Britain are those made by Matthew Paris, the great historian. Matthew, a Benedictine monk of the Abbey of St. Albans, died seven hundred years ago, in 1259, and his maps of Britain are believed to date from 1250 . Their main object was probably to show the towns and monastic guesthouses where the pilgrim could rest on his way to Dover, the usual point of departure for the Holy Land. Many of the legends on the maps are of interest; Snowdon is both named and shown by an outline of a mountain, a convention that survived on maps until the middle of the eighteenth century, when hachuring came into use. Other maps prepared by Matthew Paris which still exist include one showing the route from London to southern Italy.

When William Harvey described the circulation of the blood in his "De Motu Cordis" (1628), he referred to the Italian anatomist, Matteo Realdo Colombo, who died in 1559, and whose work, "De Re Anatomica", appeared shortly after his death. Colombo, a pupil of Vesalius, made a close study of the blood vessels of the lungs and discovered experimentally the pulmonary circulation, although he did not understand or recognize the general circulation. Colombo was appointed successor to Vesalius at Padua in 1545, but went to Pisa in the following year and taught there. Later he moved to Rome, where he was teaching when he died. 